\title{
Mixed-mode (I/II) crack initiation direction for elastic-plastic materials based on crack-tip plastic zone
}

\author{
C. M. Sharanaprabhu' ${ }^{1}$, Shashidhar K. Kudari ${ }^{2 *}$ \\ ${ }^{I}$ Research Centre, Department of Mechanical Engineering, Bapuji Institute of Engineering \& Technology, Davanagere, Karnataka, INDIA \\ ${ }^{2}$ Research Centre, Department of Mechanical Engineering, SDM College of Engineering \& Technology, Dharwad, Karnataka, INDIA \\ "Corresponding Author: e-mail: s.kudari@rediffmail.com, Tel +91-2328-235489, Fax.+91-2328-235490
}

\begin{abstract}
In this paper, crack-initiation direction for an elastic-plastic material (interstitial free steel) under mixed-mode (I/II) load is studied based on crack-tip plastic zone under monotonic load. The feasibility of using the minimum plastic zone radius (MPZR) criterion for elastic-plastic materials is also examined. The shape and size of crack-tip plastic zones have been estimated by elastic-plastic finite element analysis in a plane stress single edge notch tensile (SENT) specimen under mixed-mode (I/II) loading according to von Mises yield criteria. The results show that the minimum plastic zone sizes were not clearly identified; indicating MPZR criterion is not suitable for the analysis of elastic-plastic materials. It is shown that the crack initiation direction for elastic-plastic materials depends on the path of the maximum plastic zone size. The variation of crack initiation angle is also studied with respect to mode mixity factor and the results are found to be in good agreement with the experimental results available in the literature.
\end{abstract}

Keywords: plastic zone size, $J$ - integral, mixed mode (I/II), finite element analysis, mode mixity, SENT specimen

\section{Introduction}

The problem of crack initiation under monotonic mixed-mode loading is of great interest in the structural integrity assessment because of complex nature of actual loading condition at the crack-tip. Prediction of crack initiation and orientation with its propagation path under mixed-mode loading is much desirable for life prediction of engineering materials. The problem involving mixed mode fracture has been extensively investigated during the past decade, Nobile (2000), Sonsino (2001), Li and Chandra (2003), Ayatollahi et al. (2004), Borrego et al. (2006), Johnson and Qu (2007), Smith et al. (2008), Guo et al. (2008), Shahani and Tabatabaei (2009) and Kudari and Sharanaprabhu (2010) have analyzed the mixed mode crack initiation and orientation problems. Several criteria have been proposed for predicting crack initiation angles under Linear Elastic Fracture Mechanics (LEFM) regime. Some important criteria are maximum tangential stress criterion proposed by Erdogan and Sih (1963), and minimum strain energy density criterion proposed by Sih (1974).

It is well known that, the ductile engineering materials develop a plastically deformed region ahead of a crack-tip referred as plastic zone. This zone contains damage that leads to either a total or progressive fracture depending on the properties of the material. The growth of the crack is linked to the existence of this plastic zone at the crack-tip, whose formation and development are accompanied by energy dissipation. The fracture analysis of a material requires a clear understanding of the plastic zone morphology, deformation and stress fields ahead of the crack-tip. Determination of crack initiation angle based on crack-tip plastic zone emerged recently. Golos and Wasiluk (2000) suggested a criterion for crack initiation angles based on the minimum radius of the plastic zone. Kahn and Khraisheh (2004) and Bian and Kim (2004) proposed a minimum plastic zone radius (MPZR) criterion for crack initiation angle based on the analytical estimations of crack-tip plastic zone size considering von-Mises yield criteria. In mixed mode fracture, Kahn and Khraisheh (2004) and Bian and Kim (2004) have shown that the crack initiation angle depends on the loading angle. Benrahou et al. (2007) have identified that the type of loading alters the shape and size of the crack- 
tip plastic zone. In the earlier works (Kahn and Khraisheh, 2004 and Bian and Kim, 2004) the estimates of plastic zone size were done by choosing only LEFM parameter, stress intensity factor, which is valid only in small-scale yielding (SSY) conditions.

However, the study of the plastic zones for elastic-plastic materials demands examination using an elastic-plastic fracture mechanics (EPFM) parameter, $J$-integral. Some reports on the estimation on plastic zone sizes (PZS) together with the $J$ - integral are available in the work of Kuang and Chen (1996), Yuan and Broks (1998), and Benguediab et al. (2001) for mode-I type of specimens. Kudari et al. (2007) have clearly shown the variation of PZS with respect to the $J$-integral in detail for various geometries of mode-I fracture specimens. Arun Roy and Narasimhan (1997) have computed the $J$-dominance in mixed mode ductile fracture specimens such as Compact Tension Shear (CTS), four point bend (4PB) and Modified Compact Tension specimen. Pirondi and Dalle (2001) have proposed the relationship between crack-tip displacement vector and $J$ for CTS specimen. Li et al. (2004) originated the $J-M_{p}$ based criteria for bifurcation assessment of a crack in elastic-plastic materials under mixed mode (I/II) loading. In this paper, an effort is made to extend the work of Bian and Kim (2004) on the mixed mode crack initiation angle, for elastic-plastic materials. Finite element method is used to determine the crack-tip plastic zone under elasticplastic analysis. The objectives of this work are: (i) to evaluate the shape and size of elastic-plastic crack-tip plastic zones (mixed mode-I/II) with respect to the $J$ integral, (ii) to examine the suitability of MPZR criterion for elastic-plastic materials, and (iii) to propose a possible criterion for estimating the mixed mode crack initiation angle for elastic-plastic materials.

\section{Finite element analysis}

The general-purpose finite element (FE) code ABAQUS (2004) is used in this study. The Single Edge Notch Tensile (SENT) specimen geometry (Mohanty et al. 2008) is used in this analysis and is shown in Fig.1 (a). The load is applied at various angles $(\beta), 0^{\circ}$ (pure mode-I), $18^{\circ}, 36^{\circ}, 54^{\circ}, 72^{\circ}$ and $90^{\circ}$ (pure mode-II) to study the plastic deformation ahead of the crack-tip. In the experimental analyses (Mohanty et al. 2008, Borroego et al. 2006) the specimens were given mixed mode load with the help of a loading Jig. In the present FE analysis, the loading on the specimen, carried out with the help of a jig in experiments is simulated by applying uni-axial forces at the loading holes (Fig.1b). The force and displacement boundary condition as used in the work of Borroego et al. (2006) for compact tensile and shear (CTS) specimen is extended for the SENT specimen in this FE analysis. The specimen loading at various angles $(\beta)$ is ascertained by applying uniaxial loads $F_{l}$ to $F_{6}$ as shown in the Fig.1(b), estimated by equations (1)-(3) as given below. The displacement boundary condition as shown in Fig.1(b) is provided to avoid rigid body movement without affecting the global rigidity of the specimen (Borroego et al., 2006).



(a)

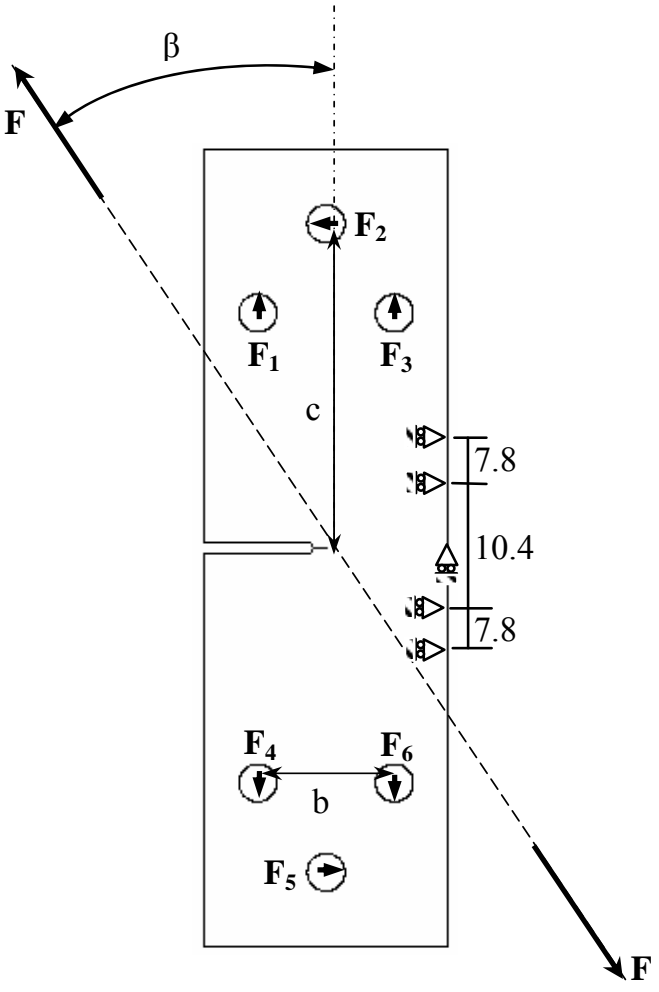

(b)

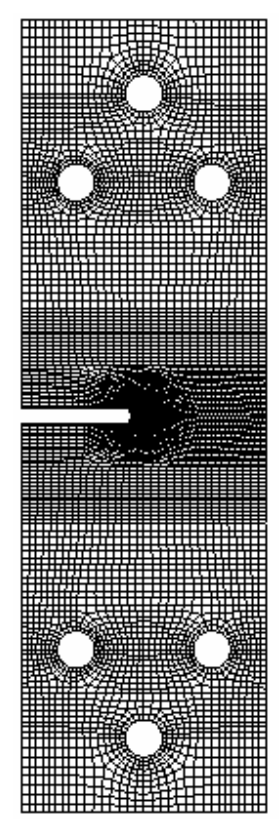

(c)

Figure 1.(a) Specimen configuration used in the analysis (all dimensions in $\mathrm{mm}$ ), thickness $=3 \mathrm{~mm}$. (b) Loading and boundary conditions, (c) FE mesh used in the analysis. 


$$
\begin{aligned}
& F_{1}=F_{6}=F\left(\frac{1}{2} \cos \beta+\frac{c}{b} \sin \beta\right) \\
& F_{2}=F_{5}=F \sin \beta \\
& F_{3}=F_{4}=F\left(\frac{1}{2} \cos \beta-\frac{c}{b} \sin \beta\right)
\end{aligned}
$$

Where, $F$ is the total applied load, $\beta$ is the loading angle, $b$ and $c$ are the dimensions shown in the Fig.1(b).

A series of elastic-plastic finite element computations have been made on the SENT specimen (Fig. $1 \mathrm{a}$ ) having $a / W=0.5$ considering the full specimen geometry due to the unsymmetrical loading. A typical two-dimensional FE mesh used in the analysis is shown in Fig.1(c). The analysis domain is descritized using 7636 number of 8-noded isoparametric 2D plane stress reduced integration solid elements (CPS8R in ABAQUS). This kind of elements is used in the work of Yun-Jae Kim et al. (2004) for computation of $J$ integral. In this $\mathrm{FE}$ analysis, interstitial-free (IF) steel possessing yield strength, $\sigma_{y}=155 \mathrm{MPa}$, ultimate strength, $\sigma_{u}=275 \mathrm{MPa}$, poisons ratio, $v=0.3$, Ramberg-Osgood strain hardening parameter, $N=3.358$ and elastic modulus, $E=197 \mathrm{GPa}$ (Kudari et al. 2007), has been considered. The material response in the plastic region was modeled as multi-linear by taking twenty divisions of plastic portion of true stress-strain curve of the material as shown in Fig.2. The magnitude of $J$ has been evaluated for a path at a specific loading condition using the expression (Rice 1968):

$$
\begin{aligned}
& J=\int_{\Gamma}\left(W d y-T_{i} \frac{\partial u_{i}}{\partial x} d s\right) \\
& W=\int_{0}^{\varepsilon} \sigma_{i j} d \varepsilon_{i j}, \quad T_{i}=\sigma_{i j} n_{j}
\end{aligned}
$$

Where $W$ is the strain energy density, $T_{i}$ is the surface traction vector, $u_{i}$ is the displacement vector and $s$ is the element of arc length along the contour $\Gamma$. The magnitudes of $J$ integrals were extracted using a contour integral with the general purpose FE code ABAQUS (2004). In this analysis, $J$ is computed using Eq.(4) based on the domain integral along five contours. In this Finite element analysis it is observed that the outer four contours gave almost path independent values of $J$. Hence, in this study, the average value of $J$ is obtained using the results from the outer four contours, which is used for further analysis.

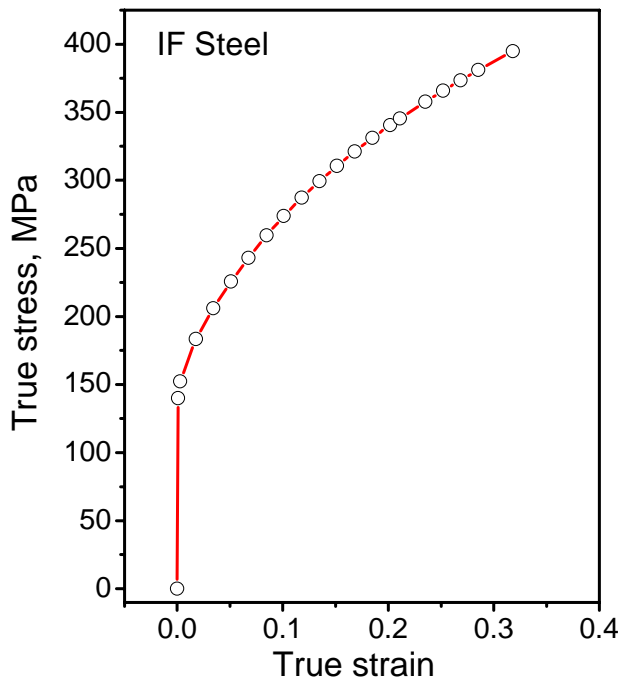

Figure 2. Multilinear stress-strain curve used in the elastic-plastic FE analysis.

\section{Results and Discussions}

The load was applied on the specimen to estimate the $J$ integral and to study the plastic zone shape and size ahead of the cracktip. A typical variation of J-integral $(J)$ with the applied load $(F)$ for various loading angles is shown in Fig.3. The nature of variation of $J$ vs. $F$ (Fig.3a) is in good agreement with similar earlier results by Arun Roy and Narasimhan (1997). It is observed from Fig.3(a) that, $J$ appears to be independent of loading angle $(\beta)$ for $F<4.3 \mathrm{kN}$ but, for $F>4.3 \mathrm{kN} J$ increases exponentially with respect to applied load $(F)$. To find the clarity in this observation, variation $J v s . F$ has been plotted for $F<5 \mathrm{kN}$ in Fig. $3($ b). This plot indicates that: (i) only for $F=4.3 \mathrm{kN} J$ is independent of $F$ for various $\beta$ and (ii) for any magnitude of $F<4.3 \mathrm{kN}, J$ 
depends on the loading angle, though the dependency is insignificantly small. It is observed from Fig.3(a) that specimen withstands maximum load and develops higher magnitude of $J$ for $\beta=0^{\circ}$ (mode-I) than other loading angles.
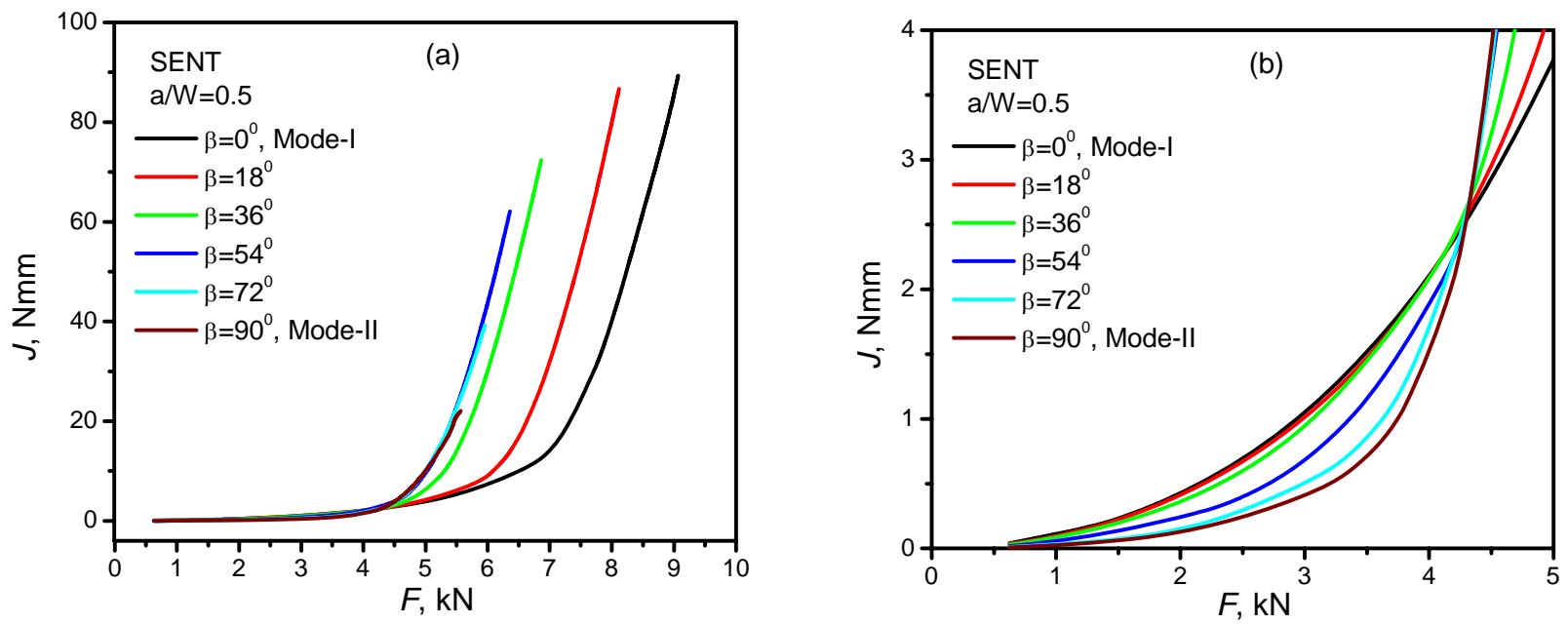

Figure 3. A typical variation of $J$ with $F$ (a) for full load (b) for load $<5 \mathrm{kN}$

Next, the shape of the plastic zone ahead of the crack-tip has been ascertained by plotting iso-contours of the effective stress, which causes yielding according to von Mises criterion (Gdoutos and Papkatalis, 1987). The sequential development of crack-tip plastic zone in the SENT specimen has been obtained by superimposing the plastic zone contours with increasing $J$ values. For simplicity the displacement scaling in these specimens are set to zero. Typical shapes of plastic zones for $\beta=0^{\circ}$ to $90^{\circ}$ are shown in Fig.4 (a) to Fig.4 (f). The plastic zone shapes have been also obtained for higher magnitudes of $J$, but it is observed that for higher magnitudes of $J$ the crack-tip plastic zones merge with plastic zones produced due to support boundary conditions, which are not shown in Fig.4. The Fig.4 indicates that the shape of plastic zone is affected by the loading angle and the plastic zone is found to be maximum ahead of the crack-tip due to the effect of plasticity. It is observed from Fig.4 that for $\beta=0^{\circ}$ (Mode-I) the shape of plastic zone is elliptical and is in good agreement with the results of Kudari et al. (2007). For $\beta=90^{\circ}$ (Mode-II) the plastic zone stretches along the ligament because of shear loading. The Fig.4 show that the minimum plastic zone size is not clearly identified as in the case of elastic analysis shown by Bin and Kim (2004) and Sharanaprabhu and Kudari (2009). Hence, the results obtained in this analysis infer that the minimum plastic zone radius (MPZR) criterion to estimate the crack initiation angle is not appropriate for the analysis of elastic-plastic materials. It is well known that the crack in elastic-plastic materials propagates due to nucleation, growth and coalescence of voids in the crack-tip process zone within the plastic zone. The nucleation, growth and coalescence are controlled by plastic strain in the process zone, indicating that the failure direction or crack initiation direction for elastic-plastic materials should be controlled by plastic strain in the process zone. In this FE analysis it is noted that, the plastic strain is found to be highest for the direction in which the plastic zone size is maximum. Based on this hypothesis, it is considered that crack propagation initiates along the direction of maximum plastic zone size for elastic-plastic materials. Further, the size of maximum plastic zone $\left(r_{o}\right)$ and the angle at which maximum plastic zone occur $\left(\theta_{o}\right)$ for various plastic zone contours obtained in this analysis are measured. The plot showing the variation of maximum plastic zone size, $r_{o} v s . J$ is shown in Fig.5. This figure shows that $r_{o} v s$. $J$ is apparently independent of loading angle. It is known that for small scale yielding (SSY) condition the allowable plastic zone size is one sixteenth of the ligament (Tracey, 1976), which is marked in the Fig.5 to demarcate SSY from LSY. This shows that for SSY condition, $r_{o}<1.3 \mathrm{~mm}$ and $J<1.3 \mathrm{Nmm}$. From Fig. 5 one can find the magnitude of $r_{o}$ for a particular $J$ or vice versa. To obtain such a relation the data in Fig. 5 is fit by a third degree polynomial. The resulting analytical expression is as given below.

$$
r_{o}=0.8121+0.8733(J)-0.0211(J)^{2}-2.023 E-4(J)^{3}
$$

The polynomial fit (Eq.5) is shown in Fig.5 by a red line, which shows an excellent fit to the present FE results for various $\beta$. The proposed Eq.(6) can be useful to the researchers and industrial scientists to predict the maximum plastic zone size $\left(r_{o}\right)$ for SENT specimens $(a / W=0.5)$ by only knowing the magnitude of $J$ or vice versa for the steel considered in this analysis or any elasticplastic materials having $N$ approximately between 3 and 4 . 

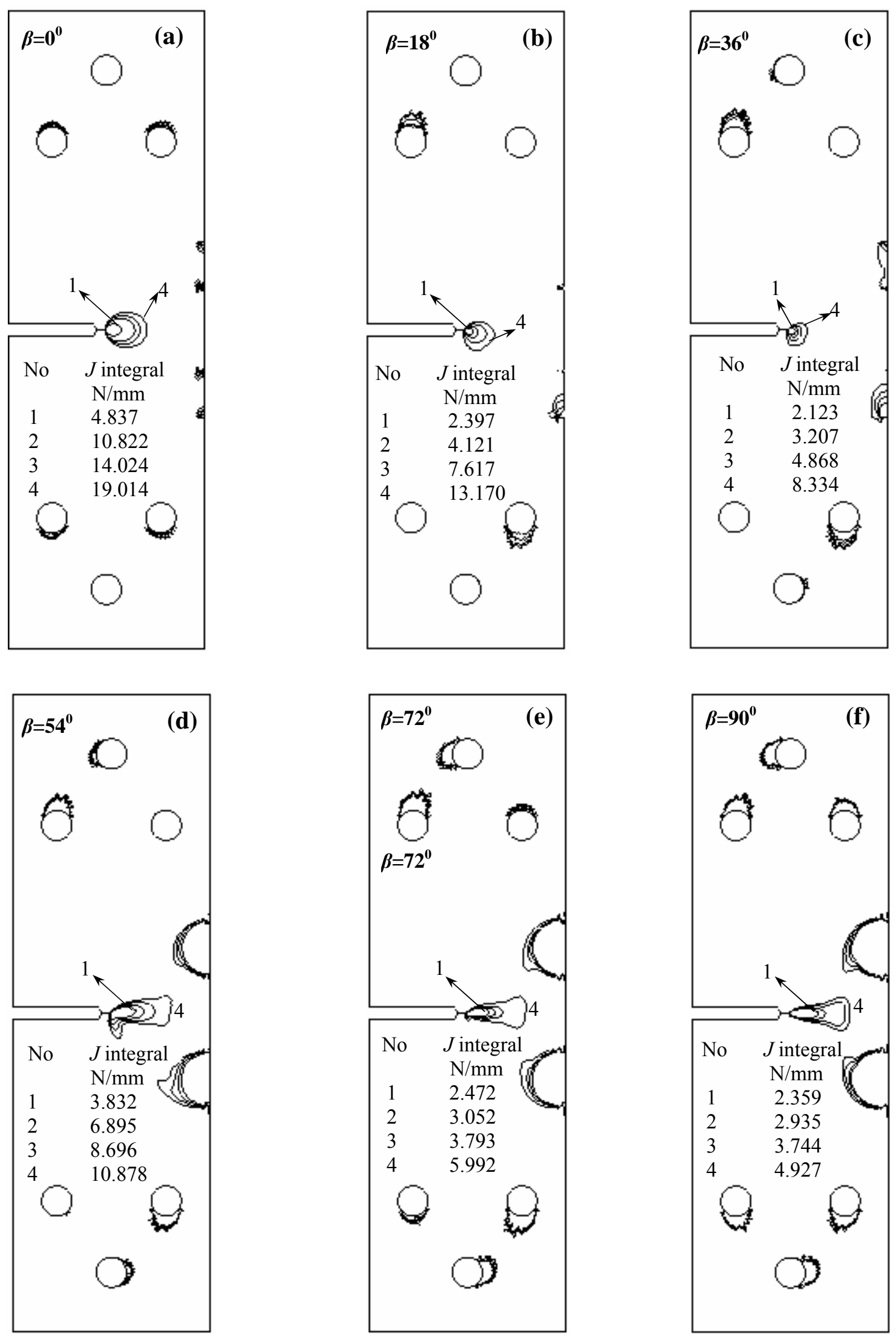

Figure 4. Typical shapes of sequential plastic zone shapes for various loading 


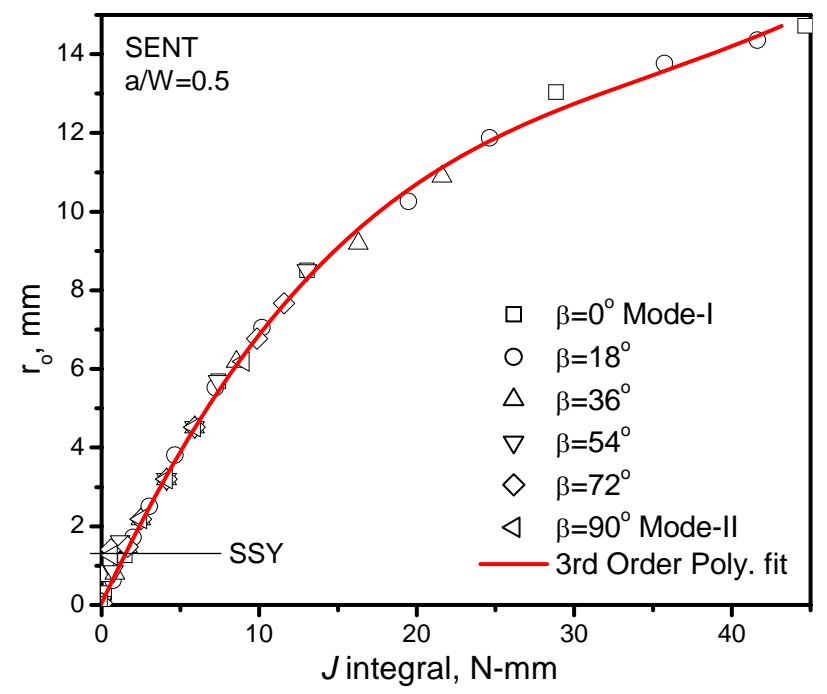

Figure 5. A typical variation of $r_{0} v s . J$ for various loading angles

Based on the hypothesis that the crack initiates at the direction of maximum plastic zone size the crack initiation/deflection angles have been estimated using the plastic zones for various loading angles. The variation of crack-deflection angle vs. loading angle is shown in the Fig.6 for various applied loads. This figure indicates that crack-deflection angle is independent of applied load. It increases from $0^{\circ}$ to $26^{\circ}$ for $\beta \leq 36^{\circ}$, then the $\theta_{o}$ shifts from $26^{\circ}$ to $0^{\circ}$ for $54^{\circ}>\beta<90^{\circ}$. This nature of variation of $\theta_{o}$ shown in Fig.6 is inconsistent with the similar results obtained based on MPZR criterion (Bian and Kim, 2004, Kahn and Khraisheh, 2004), which may be attributed to the consideration of elastic-plastic analysis in this work and elastic analysis in the work of Bian and Kim (2004) and Kahn and Khraisheh (2004).

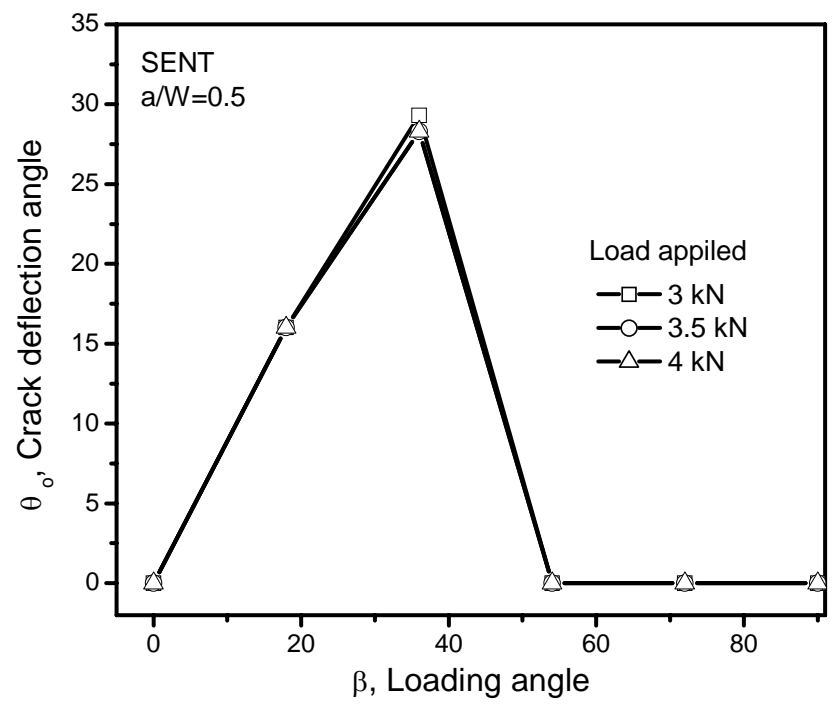

Figure 6. A typical variation of $\theta_{0} v s . \beta$ for various load steps

To validate the finite element analysis results presented in this study (Fig.6), the FE results are verified with the available experimental results of Pirondi and Dalle (2001). Pirondi and Dalle (2001) have shown the variation of crack deflection angle estimated experimentally using $4 \mathrm{~mm}$ thick CTS specimens for the ductile material (fine grained structural steel StE 550), with respect to elastic mode mixity factor $\left(M_{e}\right)$. In mixed mode (I/II) loading, the elastic mode mixity factor is defined as (Shih, 1974):

$$
M_{e}=(2 / \pi) \arctan \left(K_{I} / K_{I I}\right)
$$

$M_{e}$ ranges from 0 to 1 , with $M_{e}=0$ for pure mode-II, $M_{e}=1$ for pure mode-I, which can be used instead of loading angle $\beta$ for elastic materials. For analysis of elastic plastic materials one can use plastic mixity factor, $M_{p}$ (Shih, 1974) as: 


$$
M_{p}=\lim _{r \rightarrow 0} \frac{2}{\pi} \tan ^{-1}\left\{\frac{\sigma_{\theta \theta}(r, \theta=0)}{\sigma_{r \theta}(r, \theta=0)}\right\}=\lim _{r \rightarrow 0} \frac{2}{\pi} \arctan \left\{\frac{\sigma_{\theta \theta}(r, \theta=0)}{\sigma_{r \theta}(r, \theta=0)}\right\}
$$

$M_{p}$ also ranges from 0 to 1 , with $M_{p}=0$ for pure mode-II, $M_{p}=1$ for pure mode-I, which can be used instead of loading angle $\beta$ for elastic-plastic materials. In the work of Pirondi and Dalle (2001) the elastic mode mixity ratio $M_{e}$ is adopted instead of plastic mixity factor $M_{p}$ because of its simplicity. It is also known that $M_{p}$ practically does not depend on $N$ generally for ductile steels (Pirondi and Dalle, 2001). In this analysis $M_{p}$ is computed by elastic-plastic analysis and $M_{e}$ is computed by a separate elastic FE analysis using in equations (7) and (6) respectively. The computed $M_{e}$ and $M_{p}$ for the SENT specimen geometry are plotted in Fig.7 along with the results of Shih, (1974). This figure indicates that the relation between $M_{e}$ and $M_{p}$ are in excellent agreement with the results of Shih (1974) for $N=3$. Hence, Fig.7 gives an excellent validation of the FE results on $M_{e}$ and $M_{p}$ computed in this work.

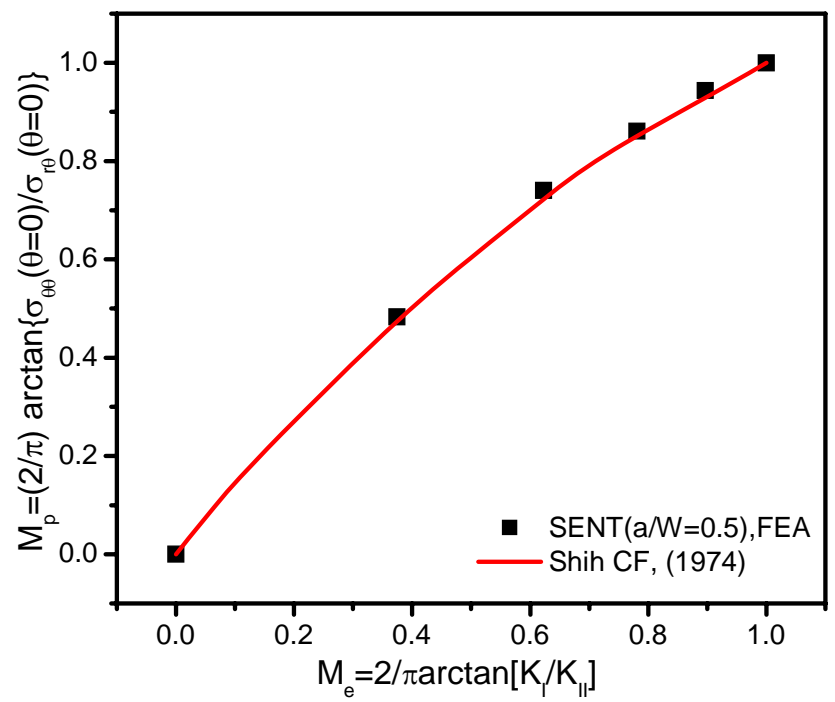

Figure 7. Load mixity $M_{p}$ vs. $M_{e}$

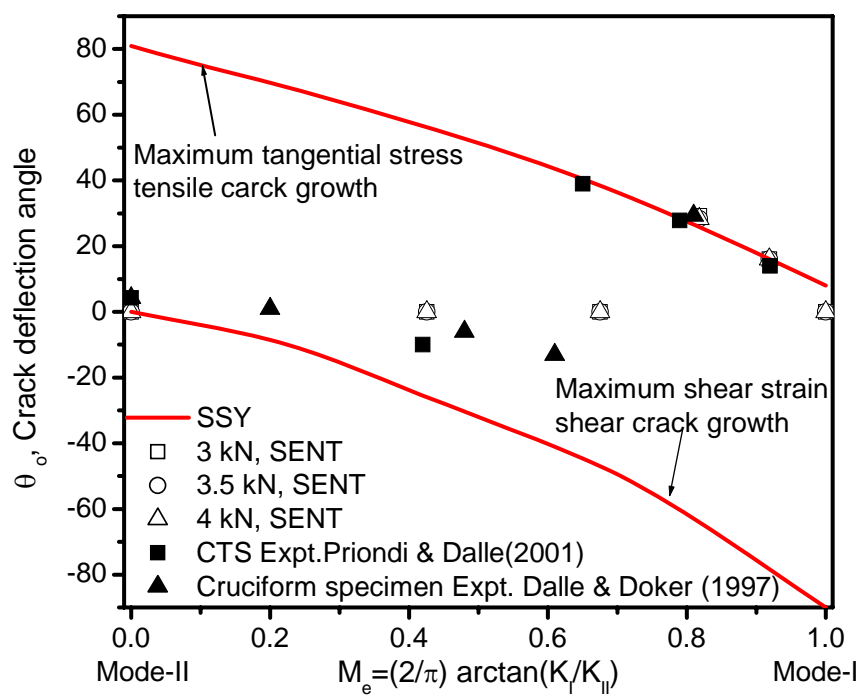

Figure 8. A typical variation of $\theta_{0} v s . M_{e}$ for various load steps

The magnitudes of $M_{e}$ and the crack deflection angle estimated in the present work are superimposed on the similar plot containing experimental results and maximum tangential stress and maximum shear strain criterion from the work of Priondi and Dalle (2001) in Fig.8. This figure indicates that the results on crack deflection angle on SENT specimen are in good agreement with the experimental results of Priondi and Dalle (2001) for CTS specimen and, Dalle and Doker (1997) for Cruciform specimen. The small deviation in present results and results presented by Priondi and Dalle (2001) may be attributed to the geometry of the 
specimen used in the analysis. Figure 8 shows that for mode $M_{e}<0.42$ the crack deflection angle $\left(\theta_{o}\right)$ better fits to the maximum shear strain criterion, where the shear load on the specimen is maximum. For mode $M_{e}>0.68$ the crack deflection angle better fits the maximum tangential stress criterion, where the opening load dominate. $0.42>M_{e}<0.68$ may be a case of transition from maximum shear strain criterion to maximum tangential stress criterion. The results presented in this study, show that for dominating tensile loads $(\beta \cong 0)$ crack initiation follows maximum tangential stress criterion and for dominating shear loads $(\beta \cong 90)$ it follows maximum shear strain criterion. The authors consider the results presented in this paper are premature to explain the crack initiation criterion for elastic-plastic materials. Further, this kind of study has to conducted for various mixed mode specimen geometries and various elastic-plastic materials having varied strain hardening parameter $(N)$ to clearly understand the crack initiation criterion based on maximum plastic zone size for elastic-plastic materials. But, from this work it is very much clear that the MPZR criterion for crack initiation direction is only suitable for materials under elastic analysis (LEFM), and it is not appropriate for the use of elastic-plastic materials.

\title{
4. Conclusions
}

The following conclusions are drawn from the present study:

o The MPZR criterion is not suitable for the analysis crack initiation direction for elastic-plastic materials

o Possibly, the crack initiates along the path of maximum plastic zone size for elastic-plastic materials

o The relationship between maximum plastic zone along the crack plane $\left(r_{\mathrm{o}}\right)$ and $J$ integral is proposed for a SENT specimen

o The crack deflection angle $\left(\theta_{\mathrm{o}}\right)$, better fits for maximum shear strain criterion for $M_{e}<0.42$ and it fits maximum tangential stress criterion for $M_{e}>0.68$

\author{
Nomenclature \\ a crack length \\ $K_{I} \quad$ mode-I stress intensity factor \\ $F \quad$ uniaxial applied load \\ $F_{1}-F_{6} \quad$ Force applied on specimen loading holes (Fig.1) \\ $K_{I I} \quad$ mode-II stress intensity factor \\ $J \quad$ J-integral \\ $M_{e} \quad$ elastic mode mixity \\ $M_{p} \quad$ plastic mode mixity \\ $N \quad$ Ramberg Osgood strain hardening constant \\ $r_{0} \quad$ plastic zone size \\ $W \quad$ width of the specimen \\ $\beta \quad$ loading angle \\ $\theta_{o} \quad$ crack initiation/deflection angle \\ Abbreviations \\ CTS compact tension shear \\ EPFM elastic plastic fracture mechanics \\ FE Finite element \\ FEA finite element analysis \\ LEFM linear elastic fracture mechanics \\ MPZR minimum plastic zone radius \\ SENT single edge notch tension \\ 4 PB four point bend
}

\section{Acknowledgment}

Authors gratefully acknowledge the computational facilities provided by the Research Centre, B V B College of Engineering \& Technology, Hubli-580 031, India.

\section{References}

ABAQUS, 2004, Version 6.5-1. Hibbitt, Karlsson \& Sorensen, Inc.

Arun Roy Y., Narashimhan R., 1997. J-Dominance in mixed mode ductile fracture specimens. International Journal of Fracture, Vol. 88, pp. 259-279.

Ayatollahi M., R., Smith D., J., Pavier M., J., 2004. Effect of constraint on the initiation of ductile fracture in shear loading. Key

Engineering Materials, Vol. 261, pp. 183-188. 
Benguediab M., Belhouri M., Ranganathan N., 2001. Computation of the plastic zone size in mode-I elasto-plastic behavior material. Journal of Material Science and Technology, Vol. 9, pp. 134-141.

Benrahou K., H., Benguediab M., Belhouri M., Nait-Abdelaziz, Imad A., 2007. Estimation of plastic zone by finite element method under mixed mode (I and II) loading. Computational Materials Science, Vol. 38, pp. 595-601.

Bian L. C., Kim K., S., 2004. The minimum plastic zone radius criterion for crack initiation direction applied to surface cracks and through-cracks under mixed mode loading. International Journal of Fatigue, Vol. 26, pp. 1169-1178.

Borrego L., P., Antunes F.,V., Costa J., M., Ferreira J., M., 2006. Mixed-mode fatigue crack growth behaviour in aluminium alloy. International Journal of Fatigue, Vol. 28, pp. 618-626.

Dalle D., C., Doker H., 1997. Plane stress crack resistance curves for an inclined crack under biaxial loading. In: Kalluri S, Bonacuse P J, editors. Multiaxial Fatigue and Deformation Testing Techniques, ASTM STP 1280. ASTM Philadelphia. pp. 243-263.

Erdogan F., Sih G., C., 1963. On the crack extension in plates under plane loading and transverse shear. Transactions of the ASME, Journal of Basic Engineering, Vol. 85D, pp. 519-527.

Gdoutos E., E., Papakalitakis G., 1987. Crack growth initiation in elastic-plastic materials. International Journal of Fracture, Vol. 32, pp. 143-156.

Golos K., Wasiluk B., 2000. Role of plastic zone in crack growth direction criterion under mixed mode loading. International Journal of Fracture, Vol. 102, pp. 341-353.

Guo W., Dong H., Yang Z., 2008. Experimental investigation of thickness effects on mixed-mode-i/ii fracture of an aluminum alloy. Condensed Matters Materials Science, arXiv: 0807.1577, pp.1-44.

Johnson J., Qu J., 2007. An interaction integral method for computing mixed mode stress intensity factors for curved bimaterial interface cracks in non-uniform temperature fields. Engineering Fracture Mechanics, Vol. 74, pp. 2282-2291.

Kahan S., M., A., Khraisheh M., K., 2004. A new criterion for mixed mode fracture initiation based on crack-tip plastic core region. International Journal of Plasticity, Vol.20, pp.55-84.

Kuang J., H., Chen Y., C., 1996. The values of J-integral within the plastic zone. Engineering Fracture Mechanics, Vol.55, pp. 869-881.

Kudari S., K., Maiti B., Ray K., K.,2007. The effect of specimen geometry on plastic zone size: a study using the J integral. Journal of Strain Analysis, Vol.42, pp.125-136.

Kudari, S., K., Sharanaprabhu C., M., 2010. On the relationship between stress intensity factor (K) and minimum plastic zone radius (MPZR) for four point bend specimen under mixed mode loading, International Journal of Engineering, Science and Technology, Vol.2, No. 5, pp. 13-22.

Li H., Chandra N., 2003. Analysis of crack growth and crack-tip plasticity in ductile materials using cohesive zone models. International journal of plasticity, Vol. 19, pp.849-882.

Li J., Zhang X., Recho N., 2004. J-Mp based criteria for bifurcation assessment of a crack in elastic-plastic materials under mixed mode I-II loading. Engineering Fracture Mechanics, Vol.71, pp.329-343.

Mohanty L., R., Verma B., B., Ray P., K., 2008. Evaluation of overload-induced fatigue crack growth retardation parameters using an exponential model, International Journal of Fracture, Vol.75, pp.3941-3952

Nobile L., 2000. Mixed mode crack initiation and direction in beams with edge crack. Theoretical and Applied Fracture Mechanics, Vol. 33, pp.107-116.

Pirondi A., Dalle D., 2001. Characterisation of ductile mixed-mode fracture with the crack-tip displacement vector. Engineering Fracture Mechanics, Vol. 68, pp.1385-1402.

Rice J., R., 1968. A path independent integral and the approximate analysis of strain concentration by notches and cracks. Transactions of the ASME, Journal of Applied Mechanics, Vol.35, pp.519-527.

Shahani A., R., Tabatabaei S., A., 2009. Effect of T-stress on the fracture of a four point bend specimen. Materials and Design, Vol.30, pp.2630-2635.

Sharanaprabhu C., M., Kudari S., K., 2009. Finite Element Analysis of Minimum Plastic Zone Radius criterion for crack initiation direction under mixed mode loading. AIP Conf. Proc. Vol. 1138, pp.13-22.

Shih C., F., 1974. Small-scale yielding of mixed mode plane strain crack problems. ASTM STP 560, ASTM Philadelphia, pp.187-210.

Sih G.,C., 1974. Strain-energy-density factor applied to mixed mode crack problems. International Journal of Fracture, Vol.10(3), pp. 305-321.

Smith D., J., Swankie T., D., Pavier M., J., Smith M., C., 2008. The effect of specimen dimensions on mixed mode ductile fracture. Engineering Fracture Mechanics, Vol.75, pp.4394-4409.

Sonsino C., M., 2001. Influence of load and deformation-controlled multiaxial tests on fatigue life to crack initiation. International Journal of Fatigue, Vol.23, pp.159-167.

Tracey D., 1976, Finite elements solutions for crack-tip behavior in small scale yielding. Journal of Engineering Materials and Technology, Vol. 98, pp.146-151.

Wasiluk B., Golos K., 2000. Prediction of crack growth direction under plane stress for mixed mode I and II loading. Fatigue and Fracture of Engineering Materials and Structures, Vol.23, pp.381-386. 
Yuan H., Brocks W., 1998. Quantification of constraints effects in elastic-plastic crack fronts fields. Journal of Mechanics and Physics of Solids, Vol. 46, pp.219-241.

\section{Biographical notes}

C. M. Sharanaprabhu is a Lecturer in the Department of Mechanical Engineering, Bapuji Institute of Engineering \& Technology, Davangere, India. He is pursuing Ph.D at Research Centre, Department of Mechanical Engineering, B V B College of Engineering \& Technology, Hubli, affiliated to Visveshwaraya Technological University, Karnataka, India.

Dr. S. K. Kudari received M. Tech. and Ph.D. from Indian Institute of Technology, Kharagpur, India in 1995 and 2004, respectively. He has more than 22 years of experience in teaching and research. He is working as a Professor in the Department of Mechanical Engineering, SDM College of Engineering \& Technology, Dharwad. His research interests include Stress analysis and Fracture Mechanics. He is a Member of IE (India), ISTE (India), ISME, IAENG, ESIS, ISTAM. He has delivered several guest lecturers in reputed Institutes in his research areas and has several technical publications to his credit.

Received November 2010

Accepted December 2010

Final acceptance in revised form December 2010 